\title{
A LIVRARIA PÚBLICA DA BAHIA EM 1818: OBRAS DE HISTÓRIA.
}

\author{
MARIA BEATRIZ NIZZA DA SILVA \\ Do Departamento de História da Faculdade de Filoso- \\ fia, Letras e Ciências Humanas da Universidade de \\ São Paulo.
}

Cremos que a história da cultura brasileira deve tornar-se mais minuciosa e profunda, acompanhando os trabalhos que se têm feito em história econômica ou social. Não há mais lugar para generalizações apressadas nem para descrições superficiais e se a história literária se encontra privilegiada pelos estudos de Antônio Cândido ou de José Aderaldo Castello é urgente que as demais áreas da cultura brasileira sejam analisadas com idêntico rigor. Este pensamento nos levou a interessar-nos pelos catálogos de bibliotecas brasileiras oitocentistas, principalmente por aquêles que foram elaborados poucos anos depois da criação de tais núcleos culturais, dado que evitaríamos assim o problema metodológico levantado pelas aquisições sucessivas de livros ao longo do século. Ao ser inaugurada, uma biblioteca possui um acêrvo que pressupõe certas opções culturais, pois de uma infinidade de obras foram escolhidas apenas algumas, que revelam os interêsses predominantes ou as necessidades culturais.

Iniciamos, pois, com êste artigo uma série de estudos sôbre o conteúdo de algumas bibliotecas das primeiras décadas do século XIX, cujos catálogos manuscritos nos foram de mais fácil acesso. Na seção de manuscritos da Biblioteca Nacional do Rio encontra-se o Catálogo dos livros, que se acham na Livraria Pública da Cidade da Bahia, em maio de 1818 , no fim do qual lemos a seguinte nota:

"Esta relação é ùnicamente dos volumes completos da Biblioteca, que montam ao número de 5.361. Os truncados montam a 426". Explica ainda o autor do catálogo: "além dos sobreditos volumes há pouco chegou de Havre de Grace um grande caixote de livros, que ainda se acham por ora em poder do Administrador o Pe. Francisco Agostinho, e por isso não vão incluidos neste Catálogo". 
A biblioteca baiana possuia obras literárias (literaturas portuguêsa, inglêsa, francesa, principalmente, além de uma abundante coleção de livros de viagens), filosóficas, políticas (incluindo-se nesta rubrica os tratados de economia política, de comércio, de agricultura, de teoria monetária), científicas (matemática, astronomia, física, química, ciência do homem, zoologia, botânica, mineralogia, geografia e principalmente medicina), alguns tratados sôbre as as artes e as técnicas, obras de teologia e finalmente obras de história.

E' a historiografia portuguêsa a mais representada, logo seguida da francesa e da inglêsa, embora a biblioteca contivesse alguns volumes de história latina, grega, espanhola e italiana. E' de notar a total ausência da historiografia alemã, quer no original, quer em tradução.

O catálogo consta de 96 páginas não numeradas e foi elaborado por ordem alfabética simultâneamente de autores e de títulos. Jamais são indicados o local e a data da edição. Quer os nomes de autores quer os títulos são escritos resumidamente, e por vêzes com êrros. Estes inconvenientes tornam por vêzes impossível a identificação da obra e no decorrer do nosso artigo teremos o cuidado de assinalar as obras que não puderam ser identificadas. Sempre que pudemos, procurámos dar a data da 1a. edição, uma vez que não tínhamos meios de saber qual a edição possuida pela biblioteca.

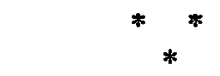

\section{HISTORIOGRAFIA PORTUGUESA.}

1. - Andrada (Francisco de), (1540 ?-1614). Crônica do muito alto e muito poderoso rei dêstes reinos de Portugal. D. João III dêste nome. Lisboa, 1613.

2. - Andrade (Diogo de Paiva de), (1576-1660). Exame de antiguiidades. Parte primeira. Repartida em doze tratados, onde se apuram histórias, opiniōes e curiosidades pertencentes ao reino de Portugal, e outras partes, desde a criação do mundo até o ano 3403. Dirigida ao Príncipe Filipe Nosso Senhor. Lisboa, 1616.

3. - Anjos (Fr. Manuel dos), (?-1653). História universal, em que se descrevem os impérios, monarquias, reinos e províncias do mundo, com muitas coisas notáveis, que há nêle. Copiada de diversos autores, cronistas aprovados, e autênticos geógrafos. Coimbra, 1652 . 
Commercial Arcaty

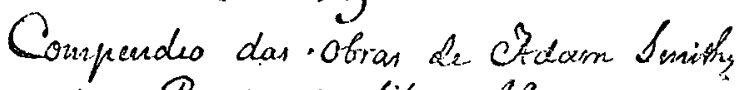

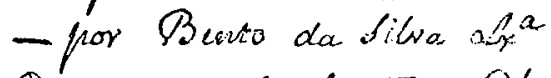

Compendia de doutrima Chirytãa, nay

- lingoas Pornuguesa e Brofilica, frelo Pe

- Socio Alipe Botundort

Compendis de resolucoong proutzcy para - o ujo dos Gratoriog.

Compendio de agricuttura de Igracio - Panlino de Choray.

Compendio de Bozanica, por Brozero Compendio das Cthingy, Le Sorá A Awro- nio da Rora.

Comperidio historico do Reino de Portrugal, por. Namago.

Compilacaso fistennatica, par Hicunter. Ioxé - Terricióa cardefo.

Ormplere Frentije of fractical neviga-tion, by Mir. Paroun.

concing Grieologia.

Concioli Allegationy forman.
Gonduite dy Conferseury

Conet. Theologia.

Conimbricense Coulegum. In tres libroz - de animán A Arigtozdiy Strainitg

Conimbricenge Collegum. In finificam - Ariytotely Staginity

Congratulacáós de Portugal an CHtany

- doo jeor frimeovog heroy pela nova liberdade.

Conjurationy des Herpantioly contre ta - Republique de Tenie, pay Sainst Royal.

Conference du Code Civil.

Confeffiony de jaint Ĉtugurtin.

Confideraitiony fur . Le gowernement de lac - Pologne, de Rouffeare

Comnoiffarce des temy, ál'. usage dy ay-tronomer, et des navigateurs.

Conquintar dos Porringueres no novo muendo.

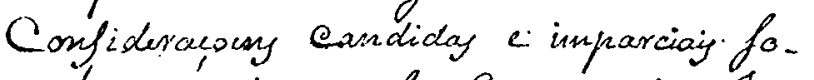

- Tre a naturcza do commercis de

- acucas, por fr Soxí Marianno 
4. - Baião (P. José Pereira), (1690-1743). Crônica d'el-rei D. Pedro I de Portugal, cognominado o Justiceiro, na forma em que a escreveu Fernão Lodes, primeiro cronista-mór, copiada fielmente do seu original, e acrescentada de nôvo ... Com muitas notícias de que 0 autor não trata. Lisboa, 1735.

5. - Barbosa (D. José), (1674-1750). Catálogo cronológico, histórico, genealógico e crítico das Rainhas de Portugal e seus filhos, etc. Lisboa, 1727 .

6. - Barradas (José Tomás de Aquino), (?-?). História do povo romano, desde a fundação de Roma até ao fim da república: dedicada ao ilmo. e exmo. sr. Francisco Xavier de Mendonça Furtado. Lisboa, 1768.

7. - Berredo (Bernardo Pereira de), ( -1748$)$. Anais históricos do Estado do Maranhão, em que se dá notícia do seu descobrimento, e tudo o mais que nêle tem sucedido desde o ano em que foi descoberto até o de 1718. Lisboa, 1749.

8. - Brandão (Fr. Francisco), (1601-1680). Quinta parte da Monarquia Lusitana, que contém a história dos primeiros vinte e três anos d'el-rei D. Dinis. Lisboa, 1650.

Sexta parte da Monarquia Lusitana, que contém a história dos últimos vinte e três anos d'el-rei D. Dinis. Lisboa, 1672.

9. - Brito (Fr. Bernardo), (1569-1617). Monarquia lusitana. Parte primeira. Que contém as histórias de Portugal desde a criação do mundo até o nascimento de nosso snr. Jesus Cristo. Dirigido ao Católico Rei Dom Filipe II do nome, Rei de Espanha. Mosteiro de Alcobaça, 1597.

Segunda parte da Monarquia Lusitana, em que se continuam as Histórias de Portugal desde o nascimento de nosso salvador Jesus Cristo até ser dado em dote ao conde D. Henrique. Dirigido ao Católico Rei D. Filipe, segundo do nome em Portugal, e terceiro em Castela. Lisboa, 1609.

10. - Castro (Damião Antônio de Lemos Faria e), (1715-1789). História geral de Portugal e suas conquistas. Lisboa, 1786-1804 .

11. - Chaves (João Rodrigues), (1704-?). História eclesiástica e cronológica da primeira idade do mundo; Flores históricas, morais e críticas, etc. Tomo I. Lisboa, 1744.

12. - Coelho (Duarte de Albuquerque), (1591-1658). Memorias Diarias de la guerra del Brasil por discurso de nueve años empeçando desde el de 1630. Madrid, 1654. 
13. - Cordeiro (P. Antônio), (1641-1722)'. História insulana das Ilhas a Portugal sujeitas no Oceano ocidental. Lisboa, 1717.

14. - Costa (Fr. Bernardo da), (?-?). Histó:ia da militar Ordem de Nosso Senhor Jesus Cristo. Tomo I. Coimbra, 1771.

15. - Deus (Fr. Gaspar da Madre de), (1730-1800). Memórias para a História da Capitania de São Vicente, hoje chamada de S. Paulo, do Estado do Brasil publicadas de ordem da Academia R. das Ciências. Lisboa, 1797.

16. - Faria (Manuel Severim de), (1583-1655). Notícias de Portugal, oferecidas a el-rei nosso senhor D. João o IV. Declaram-se as grandes comodidades que tem para crescer em gente, indústria, comércio, riquezas e fôrças militares por mar e terra. As origens de todos os apelidos e armas das familias nobres do reino. As moedas que correram nesta província do tempo dos romanos até o presente. $E$ se referem vários elogios de príncipes e varões ilustres portuguêses. Lisboa, s.d.

17. - (Ferreira, P. Manuel); (1630-?). Notícias sumárias das perseguições da missão de Conchinchina, principiada e continuada pelos padres da Companhia de Jesus. Oferecidas pelos mesmos missionários a cl-rei nosso senhor D. Pedro II. Lisboa, 1700.

18. - Freire (Francisco de Brito), (?-1692). Nova Lusitânia. História da guerra brasílica. Década primeira. Ȧ puríssima alma e saudosa memória do príncipe. D. Teodósio. Lisboa, 1675.

19. - Galvão (Antônio), ( $3-1557)$. Tratado dos descobrimentos antigos e modernos, feitos até à éra de 1550 , com os nomes particulares das pessoas que os fizeram, e em que tempo... e dos desvairados caminhos por onde a pimenta e especiaria veio da India às nossas partes. Lisboa, 1731.

Segundo Inocêncio Francisco da Silva, é a reimpressão da edição de 1563, publicada com o seguinte título: Tratado... dos diversos $e$ desvairados caminhos por onde nos tempos passados a pimenta e a especiaria veio da india ds nossas partes, e assim de todos os descobrimentos antigos $e$ modernos que são feitos em a era de 1550: Como no catálogo da biblioteca baiana o título da obra é resumidamente citado como Tratado dos descobrimentos antigos e modernos, cremos que a edição oitocentista e não a seiscentista é que fazia parte da livraria. 
20. - Gouveia (D. Fr. Antônio de), (?-1628). Jornada do Arcebispo de Goa D. Fr. Aleixo de Meneses, Primaz da India oriental, religioso da Ordem de S. Agostinho, quando foi às terras do Malabar, lugares em que moram os antigos cristãos de S. Tomé, e os tirou de muitos êrros e heresias em que estavam, etc. Recopilada de diversos tratados de pessoas de autoridade, que a tudo foram presentes: com a notícia de muitas cousas notáveis da fndia. Coimbra, 1606.

21. - Homem (Fr. Manuel), (1599-1662). Memória da disposição das armas castelhanas, que injustamente invadiram o reino de Portugal no ano de 1580; despertadora ao valor português para não temer da prudência e conselho para ordenar o presente; da prevenção e cautela para dispor o futuro. Lisboa, 1655 .

22. - Lacerda (D. Fernando Correia de), pseud. Leandro Dória Cáceres e Faria (1628-1685). Catástrofe de Portugal na deposição d'el-rei D. Afonso VI, e subrogação do príncipe D. Pedro o único... Escrita para justificação dos portuguêses. Lisboa, 1669.

23. - Lamago (Bartolomeu), Segundo Inocêncio, é um pseudônimo. (?-?). Compêndio Histórico do reino de Portugal, em que se dá razão do seu principal terreno, rios, montes e cidades com os nomes dos seus reis, etc. Lisboa, 1810.

24. - Lavanha (João Batista), (1555-1625). Quarta década de João de Barros reformada, e acrescentada com tábuas geográficas, etc. Madrid, 1615.

Nobiliario de D. Pedro, conde de Barcelos, hijo del Rey D. Dionis de Portugal, ordenado y illustrado com notas $\mathrm{y}$ indices, etc. Roma, 1640.

25. - Lobo (Roque Ferreira), (1743-1828). História da feliz aclamação do senhor rei D. João IV, com uma série cronológica dos senhores reis de Portugal. Lisboa, 1803.

26. - Machado (Diogo Barbosa), (1682-1772). Memórias para a história de Portugal, que compreendem o govêrno d'el-rei D. Sebastião,... do ano de 1554 até o ano de 1561. Lisboa, 1736-51:

27. - Mariz (D. Pedro de), (?-?). Diálogos de vária história. Em que sumàriamente se referem muitas cousas antigas de Espanha; e tôdas as mais notáveis que em Portugal aconteceram em suas gloriosas conquistas, antes e depois de ser levantado 
a Dignidade Real. E outras muitas de outros reinos, dignas de memória. Com os retratos de todos os reis de Portugal. Coimbra, 1594.

28. - Mendonça (Jerônimo de), ( $($ - P). Jornada de África: em a qual se responde a Hieronimo Franqui, e a outros, e se trata do sucesso da batalha, cativeiro, e dos que nele padeceram por não serem Mouros, com outras cousas dignas de notar. Lisboa, 1607.

29. - Monteiro (Fr. Pedro), (1662-1735). História da Santa Inquisição do reino de Portugal e suas conquistas. Parte I. Da origem das Santas Inquisições da cristandade, e da Inquisição antiga que houve neste reino, com os seus Inquisidores gerais. Livro $1^{\circ} \mathrm{Em}$ que se mostra a origem da Santa Inquisição, e seu primeiro Inquisidor geral, o patiarca S. Domingos, e de como êste impugnou e destruiu a heresia dos albigenses; de outras Inquisições que fez; e Inquisidores da sua ordem que nomeou. Lisboa, 1749.

História da Santa Inquisição, etc. Livro $2^{\circ} \mathrm{Da}$ Santa Inquisição antiga que houve neste reino, desde o senhor rei $D$. Afonso II até o govêrno do sr. rei D. João III, e nos mais de Espanha até o d'el-rei católico D. Fernando, e dos concílios gerais, cismas e heresias, que por êstes tempos houveram na igreja. Lisboa, 1750.

30. - Pereira (Antônio Pinto), ( $3-1587$ ?). História da India, no tempo em que a governou o Viso-Rei D. Luís de Ataíde. Dirigida a el-rei D. Sebastião. Coimbra, 1616.

31. - Pinheiro (José Feliciano Fernandes), (1774-1847). História Nova, e Completa da América, coligida de diversos autores. Lisboa, 1800.

32. - Sampaio (Antônio de Vilas Boas e), (1629-1701). Nobiliarquia Portuguêsa; Tratado da Nobreza hereditária e política. Oferecido ao exmo. sr. D. João da Silva, Marquês de Gouveia. Lisboa, 1676.

33. - S. Miguel (Fr. Jacinto de), (1692-?). Tratado histórico das ordens monásticas de S. Jerônimo e S. Bento. Primeira parte, Lisboa, 1739. Parte segunda, Ibid., 1749. Parte terceira, Ibid., 1761 .

34. - Serra (José Francisco Correia da), (1750-1823). Coleção de livros inéditos da História Portuguêsa dos Reinados de $\mathbf{D}$. João I, D. Duarte, D. Afonso V, e D. João II, publicados 
de ordem da Academia Real das Ciências de Lisboa. Lisboa, 1790-1824.

A biblioteca baiana só devia possuir os tomos I, II e III (publicados respectivamente em 1790, 1792 e 1793) prefaciados por Correia da Serra.

35. - Silva (Antônio de Morais e), (1756?-1825?). História de Portugal composta em inglês por uma Sociedade de Literatos, transladada em vulgar com as adiçōes da versão francesa, e notas do tradutor português. Lisboa, 1788.

36. - Silva (José Soares da), (1672-1739). Memórias para a história de Portugal, que compreendem o govêrno d'el-rei D. João I, do ano de 1383 até o de 1433. Tomo I. Lisboa, 1730.

37. - Sousa (D. Antônio Caetano de), (1674-1759). História geneạlógica da Casa Real Portuguêsa desde a sua origem até o presente, com as famílias ilustres que procedem dos Reis, e dos Sereníssimos Duques de Bragança, justificada com instrumentos. e escritores de inviolável fé. Lisboa, 1739-1748.

38. - Sousa (Manuel de Faria e), (1590-1649). Epitome de las historias portuguesas. Tomo I e II, Madrid, 1628.

Ásia portuguêsa. Tomo I, Lisboa, 1666; tomo II, ibid., 1674; tomo III, ibid., 1675.

Europa portuguesa. Segunda edicion correta, ilustrada y añadida en tantos lugares, e con tales ventajas, que es labor nueva. Tomo I, Lisboa, 1678; tomo II, ibid., 1679; tomo III, ibid., 1680.

África portuguêsa. Tomo único. Lisboa, 1681.

39. - Teles (P. Baltazar), (1595-1675). História geral da Etiópia a Alta, ou Preste João, e do que nela obraram os Padres da Companhia de Jesus, composta na mesma Etiópia pelo P. Manuel de Almeida, natural de Viseu. Coimbra, 1660.

40. - Vasconcelos (P. Inácio da Piedade e), (?-1752). História de Santarém edificada, que dá notícia da sua fundação, e das coisas mais notáveis nela sucedidas, a saber: da fundação de tôdas as suas igrejas... dos prodigiosos milagres ali sucedidos, das relíquias que encerram, das vidas $\mathrm{d}_{\mathrm{e}}$ vários santos $\mathrm{e}$ beatas, e de muitas pessoas dignas de memória, assim em virtudes, como em armas e letras, todos naturais de Santarém, etc. Partes I e II. Lisboa, 1740.

41. - Vasconcelos (P. Simão de), (1597-1671). Crônica da Companhia de Jesus do Estado do Brasil, e do que obraram seus 
filhos nesta parte do mundo. Tomo I. Da entrada da Companhia de Jesus nas partes do Brasil, e dos fundamentos que nelas lançaram e continuaram seus religiosos, enquanto ali trabalhou o P. Manuel da Nóbrega, fundador e primeiro provincial desta província, com sua vida e morte, digna de memória: e algumas notícias antecedentes, curiosas e necessárias das cousas daquele estado. Lisboa, 1663.

Outros historiadores portuguêses, mais conhecidos, se encontravam representados na biblioteca baiana: Fernão Lopes (Crônica d'el-rei D. João I); Damião de Góis (Crônica de D. Manuel); Garcia de Resende (Crônica d'el-rei D. João II) ; João de Barros (Décadas da Ásia); Duarte Nunes de Leão (Crônicas de Portugal); Couto (Décadas da Ásia).

Algumas obras constantes do catálogo não puderam contudo ser identificadas nas bibliografias a que recorremos:

1. - Ultimas ações do Duque D .Nuno, por D. João Jaime, seu estribeiro mor.

2. - Malaca conquistada pelo Grande Afonso de Albuquerque.

3. - História da fndia, ou Diálogo de um soldado antigo e velho da India.

4. - Biblioteca histórica de Portugàl, por D. João Maria.

5. - Conquistas dos portuguêses no nôvo mundo.

\section{HISTORIOGRAFIA FRANCESA.}

1. - Abrégé de l'histoire ecclésiastique (par l'abbé Racine). Colônia (Paris), 1752-1762. Segundo Barbier, os tomos XIV e $\mathrm{XV}$ desta edição são do abade Troia d'Assigny.

2. - L'art de vérifier les dates des faits historiques, chartes, etc. (par D. Maur.-François Dantine, D. Ursin Durand et D. Charles Clémencet). Paris, 1750.

3. - Banier (abade Antoine), La Mythologie et les fables expliquées par l'histoire. Paris; 1738-1740.

4. - Beauchamp (Alphonse de), Histoire du Brésil, depuis sa découverte en 1500 júsqu'en 1810: Paris, 1815.

5. - Ceillier (Dom Rémy), Histoire générale des auteurs sacrés et ecclésiastiques, qui contient leur vie, le catalogue, la criti- 
que... des diffẻrentes éditions de leurs ouvrages. Paris, 1729-1783 .

6. - Cousin d'Avallon (Charles-Yves Cousin conhecido por), Bonapartiana, ou Recueil des réponses ingénieuses ou sublimes, actions héroiques et faits mémorables de Bonaparte. Paris, ano IX, 1801.

7. - Des Vignolles (Alphonse), Chronologie de l'histoire sainte et des histoires étrangères qui la concernent, depuis la sortie d'Egypte jusqu'à la captivité de Babylone. Berlim, 1738.

8. - Dictionnaire historique, ou histoire abrégée de tous les hommes qui se sont fait un nom par le génie, les talents, les vertus, les erreurs, etc. depuis le commencement du monde jusqu'à nos jours (par Franc.-Xavier de Feller): Augsburgo (Liège), 1781.

9. - Dictionnaire historique portatif de la géographie sacrée, ancienne et moderne; ouvrage utile pour l'intelligence de l'Ancien et du Nouveau Testament, et de l'histoire de l'Église (par François Morénas). Paris, 1759.

10. - Dupin (Louis Ellies), pseud. abade de Clairval. Histoire de l'Église en abrégé, par demandes et par réponses, depuis le commencement du monde jusqu'à présent. Paris, 1714 .

11. - Du Port du Tertre (François Joachim), Histoire des conjurations, conspirations et révolutions célèbres tant anciennes que modernes. Paris, 1754-1760.

12. - Éclaircissements historiques sur les causes de la révocation de l'édit de Nantes, et sur l'état des protestants en France, depuis le commencement du règne de Louis XIV jusqu'à nos jours. Tiré des différentes archives du gouvernement (par Claude-Carloman de Rulhière). S: 1. (Paris), 1788.

13. - Fleury (abade Claude), Histoire ecclésiastique. Paris, 1691-1738 .

Discours sur l'histoire ecclésiastique. Paris, 1708.

14. - Folard (Jean-Charles de), Abrégé des Commentaires de M. de Folard sur l'histoire de Polybe par M. (G.-A. de Rohan-Chabot). Paris, 1754.

15. - Guyon (abade Claude-Marie), Histoire des: Indes orientales anciennes et modernes. Paris, 1744. 
16. - Helyot (Pierre), Histoire des ordres monastigues, religieux et militaires et des congrégations séculières de l'un et de l'autre sexe. Paris, 1714-1719.

17. - Hénault (presidente Charles-Jean-François), Nouvel abrégé chronologique de l'histoire de France. Paris, 1744.

18. - Histoire des désastres de Saint-Domingue, précédée d'un tableau du régime et des progrès de cette colonie, depuis sa fondation jusqu'à l'époque de la Révolution française, avec carte (par Mich.-Et. Descourtilz). Paris, ano III.

19. - La Clède (De), Histoire générale de Portugal. Paris, 1735.

20. - Le Beau (Charles), Histoire du Bas Empire, en commençant à Constantin le Grand. Paris, 1757-1817.

21. - Lenglet du Fresnoy (abade Nicolas), Méthode pour étudier l'histoire. Paris, 1713.

22. - Le Quien de la Neufville (Jacques), Histoire générale de Portugal. Paris, 1700.

23. - Marsy (François-Marie de), Histoire moderne des Chinois, des Japonais, des Indiens, des Persans, des Turcs, des Russiens, pour servir de suite à l'Histoire ancienne de M. Rollin. Paris, 1755-1778.

24. - Millot (abade Claude François), Éléments de l'histoire de France depuis Clovis jusqu'à Louis XV. Paris, 1768.

Eléments d'histoire générale. Paris, 1772-1773.

25. - Moreri (Louis), Le grande dictionnaire historique, ou le Mélange curieux de l'histoire sacrée et profane. Lyon, 1674.

26. - Pouchot (capitão no regimento de Béarn), Mémoires sur lá dernière guerre de l'Amérique septentrionale, entre la France et l'Angleterre, suivis d'observations, dont plusieurs sont relatives au théatre actuel de la guerre, et de nouveaux détails sur les moeurs et les usages des sauvages, avec des cartes topographiques. Yverdon, 1781.

27. - Puffendorf '(Samuel), Introduction à l'histoire moderne, générale et politique de l'univers... commencée par le baron de Puffendorf, augmentée par M. Bruzen de la Martinière. Nouv. éd.... continuée jusqu'en 1750 par $M$. de Grace (avec la collaboration de Meusnier de Querlon). Paris, 1753-1759. 
28. - Rapin de Thoyras (Paul), The History of England, as well ecclesiastical as civil, by M: de Rapin Thoyras... done into English from the French; with large and useful notes marked with an*, by $\mathrm{N}$. Tindal.

29. - Rollin (Charles), Histoire ancienne des Égyptiens, des Carthaginois, des Assyriens, des Babyloniens, des Mèdes et des Perses, des Macédoniens, des Grecs. Paris, 1731-1738.

Histoire romaine, depuis la fondation de Rome jusqu'à la bataille d'Actium, c'est-à-dire jusqu'à la fin de la République. Paris, 1738-1748.

30. - Servan (General Joseph), Histoire des guerres des Gaulois et des Français en Italie, avec le tableau des événements civils et militaires qui les accompagnèrent et leur influence sur la civilisation et les progrès de l'esprit humain, depuis Bellovèse jusqu'à la mort de Louis XII, par l'ex-adjud. gén. Auguste Jubé... depuis Louis XII jusqu'au traité d'Amiens, par Joseph Servan. Paris, ano XII - 1805 .

31. - Tableau historique de la guerre de la Révolution de France, depuis son commencement en 1792 jusqu'à la fin de 1794 . Paris, 1808.

Segundo Barbier, os dois primeiros volumes foram escritos pelo conde Phil.-Henri de Grimoard, e o terceiro pelo General Joseph Servan.

32. - Vertot (René Aubert de), Histoire des révolutions arrivées dans le gouvernement de la république romaine. 3a. ed. Haia, 1724.

Por serem obras mais conhecidas, não fizemos referência especial a $L e$ siècle de Louis XIV e Histoire de la Russie, sous Pierre le Grand, de Voltaire, nem a Considérations sur les causes de la grandeur et de. la décadence des Romainss de Montesquieu.

Algumas obras houve que não conseguimos identificar:

1. - Mémoires historiques sur la campagne du général Brune, en Batavie.

2. - Histoire générale de l'Amérique, après sa découverte, par $\mathbf{M}$. Pouron.

3. - Forfaits de la révolution, par un officier de cavalerie. Do catálogo constam ainda duas traduçōes do francês para português: 
1. - Branco (Pedro de Sousa de Castelo), Elementos da história, ou o que é necessário saber-se da cronologia, da geografia, do brạzão, da história universal, da igreja do testamento velho, das monarquias antigas, da igreja do testamento nôvo, e das monarquias novas, antes de ler a história particular: pelo abade de Vallemont. Traduzida da língua francesa na portuguêsa, e acrescentada com algumas notícias de Portugal. Lisboa, 1734-1751.

2. - Sousa (José Roberto Monteiro de Campos Coelho), História dos Judeus, escrita em grego por Flávio José, traduzida em francês por Arnault d'Andilly, e desta na língua portuguêsa. Lisboa, 1793.

Comenta Inocêncio Francisco da Silva: "A esta se ajunta a História das guerras dos judeus contra os romanos do mesmo autor, de que só se publicaram três tomos, suspendendo-se a continuação por motivo que ignoro". A biblioteca baiana possuia as duas obras.

\section{HISTORIOGRAFIA INGLESA.}

1. - Barrow (John), Abrégé chronologique, ou Histoire des découvertes faites par les européens dans les différentes parties du monde... traduit de l'anglais par M. Targe. Paris, 1766.

2. - Bryant (Jacob), (1715-1804). A New System or an analysis of ancient mythology: wherein an Attempt is made to divest tradition of fable and to reduce the truth to its original purity. Londres, 1774-1776.

3. - Coote (Charles), (1761-1835). The history of England, from the peace of 1783 to the treaty concluded at Amiens in 1802; being a continuation of Coote's History of England from the earliest dawn of record to the peace of 1783 , by the author of the former part. Londres, 1803.

4. - Edwards (Bryan), The History, civil and commercial, of the British colonies in the West Indies. Dublin, 1793.

Histoire civile et commerciale des colonies anglaises dans les Indes occidentales,... suivie d'un Tableau historique et politique de l'île de Saint-Domingue avant et depuis la Révolution française, traduit de l'anglais de Bryan Edouard par le traducteur des Voyages d'Arthur Young en France et en Italie (François Soulès). Paris, ano IX (1801). 
5. - Ferguson (Adam), (1732-1816). The History of the Progress and Termination of the Roman Republic. Londres, 1782.

6. - Gibbon (Edward), (1737-1794). The History of the decline and fall of the Roman empire. $t$. I, Londres, 1776; t. II e III, $1781 ; t$. IV, V e VI, 1788.

7. - Gordon (William), The History of the rise, progress and establishment of the independence of the United States of America. Londres, 1788.

8. - Hume (David), (1711-1776). History of England from the Invasion of Julius Caesar to the Accession of Henri VII. Londres, 1762.

Histoire de la maison de Stuart sur le trône d'Angleterre (par l'abbé Prévost). Londres, 1760.

9. - Lediard (Thomas), Histoire navale d'Angleterre, depuis la conquête des Normands en 1066, jusqu'à la fin de l'année 1734, traduite de l'anglais de Thomas Lediard (par P.-F. de Puisieux). Lyon, 1751.

10. - Orme (Robert), (1728-1801). A History of the Military Transactions, of the British Nations in Indostan, from 1745 . Londres, 1763-78.

11. - Robertson (William), (1721-1793). The History of Scotland during the Reigns of Queen Mary. and of King James VI, till his Accession to the Crown of England. With a Review of the Scotch History previous to that period; and an Appendix containing original papers. Londres, 1759:

The History of the Reign of the Emperor Charles V. With a view of the Progress of Society in Europe, from the subversion of the Roman Empire, to the beginning of the Sixteenth century. Londres, 1769.

The History of America. Londres, 1777.

An Historical Disquisition concerning the knowledge which the ancients had of India. Londres, 1791.

12.. - Rutherford (William), A view of ancient history; including the progress of litterature and the fine arts. Londres, 1809.

13. - Southey (Robert), (1774-1843). History of Brazil. Londres, 1817-22.

14. - Watson (Robert), (1730?-1781). The history of the reign of Philip the second, King of Spain. Londres, 1777.

Não pudemos identificar: 
1. - Payne's Epitome of History.

2. - History of the French Revolution.

3. - History of Mexico.

4. - Universal History from the earliest account of time.

5. - Geographical, historical, and political history of the Germany, Holland, etc.

\section{BIBLIOGRAFIA.}

Para a elaboração dêste trabalho servimo-nos principalmente do Catálogo da Biblioteca Nacional de Paris e do Catálogo da Biblioteca do Congresso e também de:

1. - Barbier (Ant.-Alex), Dictionnaire des ouvrages anonymes. 3a. ed. Paris, 1873.

2. - Brunet (Gustave), Dictionnaire des ouvrages anonymes suivi des supercheries littéraires dévoilées. Supplément à la dernière édition de ces deux ouvrages. Paris, 1889.

3. - Everyman's Dictionary of literary biography english and american. Londres, 1960.

4. - Figanière (Jorge César de), Bibliografia histórica portuguêsa, ou catálogo metódico dos autores portuguêses, e de alguns estrangeiros domiliciários em Portugal, que trataram da história civil, política e eclesiástica dêstes reinos e seus domínios, e das naçóes ultramarinas, e cujas obras correm impressas em vulgar; onde também se apontam muitos documentos e escritos anônimos que lhe dizem respeito. Lisboa, 1850.

5. - Fonseca (Martinho da), Aditamentos ao dicionáriò bibliográfico português de Inocêncio Francisco da Silva. Coimbra, 1927.

6. - Machado (Diogo Barbosa), Biblioteca Lusitana histórica, crítica, e cronológica. Na qual se compreende a notícia dos autores portuguêses, e das obras, que compuseram desde o tempo da promulgação da lei da graça até o tempo presente. Lisboa, 1741-1759.

7. - Matos (Ricardo Pinto de), Manual bibliográfico português de livros raros, clássicos e curiosos. Pôrto, 1878.

8. - Moraes (Rubens Borba de), Bibliografia brasileira do periodo colonial. São Paulo, 1969.

9. - Silva (Inocêncio Francisco da), Dicionário bibliográfico português. Lisboa, 1858-1923. 